\title{
The association between basal body temperature, plasma progesterone and the oestrous cycle in a marsupial, the Tasmanian bettong (Bettongia gaimardi)
}

\author{
R. W. Rose and S. M. Jones \\ Zoology Department, University of Tasmania, Box 252C, GPO Hobart, Tasmania 7001, Australia
}

\begin{abstract}
Basal body temperature, quantitative changes in vaginal smears and plasma concentrations of progesterone were measured during a number of oestrous cycles in Tasmanian bettongs (Bettongia gaimardi). These methods of monitoring the reproductive cycle were compared in an attempt to find a technique that allowed non-stressful assessment of the reproductive condition of the bettongs. Telemetric measurement of basal body temperature showed that there was a diurnal variation of $1.3^{\circ} \mathrm{C}$, typical of a nocturnal animal. During the oestrous cycle, there was a small, but not significant, peak in basal body temperature at oestrus (day 0 ) followed by a significant trough on day 2 . There was a significant increase on day 3 and the temperature remained raised until day 10, during which time plasma progesterone concentrations are also high; the temperature then fell 2 days before oestrus. This fall corresponds to a decrease in concentration of plasma progesterone and in the numbers of leucocytes in vaginal smears. Telemetric measurement of body temperature may be useful as a non-stressful method of monitoring the oestrous cycle in bettongs.
\end{abstract}

\section{Introduction}

The monitoring of reproductive cycles of mammals usually requires that animals are caught frequently for inspection, and that vaginal smears and blood samples for hormone analyses are collected. In the field, these methods are difficult and often stressful. The development of a technique that does not involve the frequent capture of animals would be most useful in the field, particularly for animals such as macropodid marsupials which are often nocturnal and prone to capture myopathy (Shepherd, 1990).

The variation in body temperature during the human menstrual cycle has been used for approximately 50 years as a retrospective indicator of the time of ovulation. Rhythmic variations in body temperature throughout the reproductive cycle also occur in a number of other primates including the chimpanzee (Graham et al., 1977). However, with the exception of studies on domestic and laboratory eutherian mammals, there are very few reports of this phenomenon in wild mammals; data on marsupials are particularly scarce. There is preliminary work on captive wombats, Vombatus ursinus (Peters and Rose, 1979), showing a relationship between basal body temperature and the stage of oestrus in several of these wild caught marsupials. More recently, Halse and Rose (1988) studied the fluctuations in body temperature of female brushtail possums (Trichosurus vulpecula). Although few reproductive cycles were monitored, there appeared to be little correlation between basal body temperaure and the oestrous cycle in this species.

Received 22 June 1995.
The Tasmanian bettong, Bettongia gaimardi, is a small ratkangaroo that is only found on the island of Tasmania, off the south-east coast of mainland Australia. The oestrous cycle and gestation period are of similar duration (21-22 days). After this relatively short gestation period, a single young is born that travels to the pouch and attaches itself to one of the four teats (Rose, 1987). Shortly thereafter (within $24 \mathrm{~h}$ of birth) a postpartum oestrus occurs and the resultant fertilized egg develops to the blastocyst stage before entering quiescence. This lactational quiescence continues until the last 3 weeks of pouch occupancy, or sooner if the pouch young is lost or removed experimentally (Rose, 1986). In this latter case, a new young is born 18 days after removal of pouch young (Rose, 1987).

Members of the genus Bettongia have a characteristic 'nervousness' in captivity that often results in the loss of pouch young (Tyndale-Biscoe, 1968; Rose, 1982). Newly caught Tasmanian bettongs are aggressive and nervous, particularly if handled during daylight hours; those reared in captivity are much tamer and easier to handle (Rose, 1982). The regular sampling of blood for the purpose of hormone analyses is thought to be stressful, and may lead to variations in the duration of gestation (Jones and Rose 1992).

A method that monitors the reproductive cycle of such animals without regular disturbance would be of obvious use. The availability of relatively inexpensive telemetric monitoring, coupled with data storage and computer analyses have been used recently by Rose et al. (1990) to detect diurnal body temperature rhythms in male bettongs. In the present study, similar methods were used to correlate temperature rhythms with the reproductive cycles of female Tasmanian bettongs 
which were also monitored by the more conventional means of vaginal smears and hormone sampling.

\section{Methods and Materials}

\section{Animals}

The husbandry and maintenance of the Tasmanian bettongs in captivity were as described in Rose (1982). The animals used were either reared in captivity, or well-accustomed to handling. During the telemetry experiment, nonpregnant female bettongs were maintained in the laboratory alone, in cages of one cubic metre. Three females provided relatively complete recordings of body temperature over a total of 12 oestrous cycles; the same animals were monitored subsequently for reproductive cycles by the vaginal smear method described in Rose (1987). Vaginal smears and blood samples were collected while the animals were held with males in outdoor enclosures $3 \mathrm{~m} \times 3 \mathrm{~m}$. Blood samples for assay of plasma progesterone were taken regularly from an additional nine non-pregnant females, held in outdoor enclosures. To minimize disturbance, these females were not held with males and no pregnancies occurred.

\section{Temperature recording}

Telemeters (UL81T, Austec, Edmonton) were implanted in the abdominal cavity under halothane/oxygen anaesthesia. These temperature recorders transmitted a series of 'beeps', the time interval between which was directly related to the body temperature. Each telemeter had previously been calibrated in a graded series of water baths shortly before implantation. Animals were allowed to recover for 3 days after the operation. Each telemeter transmitted at a set frequency in the $150 \mathrm{MHz}$ band. A 'black box' with a frequency scanner monitored body temperature every hour and this information was stored on computer. Subsequently the information was converted to temperature with an equation obtained from the calibration curve. The telemeters were recovered after the experiment and recalibration showed that there had been minimal drift.

\section{Statistical analyses}

Previous research showed that there is considerable individual variation in the body temperature of male bettongs (Rose et al., 1990). A repeated measures analysis of variance (ANOVA) was used to compare the variation within individual days of the oestrous cycles with the variation within individual cycles. The analysis was conducted using the computer program STATVIEW ${ }^{(\mathbb{R})}$ for Macintosh computers. Subsequently, an overall standard error of the difference between the means was calculated. The calculated mean difference between each and every day was compared with twice the overall standard error of the differrence between the means. Values greater than twice this standard error were deemed statistically significant at the $95 \%$ level. This method of analysis was suggested and approved by the departmental statistician, L. Barmuta.

\section{Blood sampling and progesterone assay}

Jones and Rose (1992) previously showed that blood sampling affects the duration of the reproductive cycle of bettongs. Therefore, blood samples were not taken during the monitoring of body temperature. Samples were obtained from twelve females during the 10 days before and the 10 days after oestrus. Although all animals were not sampled daily, at least six bettongs were sampled per day of the cycle. Blood samples ( $1 \mathrm{ml}$ ) were obtained from the lateral tail vein, centrifuged within $5 \mathrm{~min}$ of collection in a mini-centrifuge for $5 \mathrm{~min}$ at $2000 \mathrm{~g}$. Plasma samples were separated and stored in vials at $-20^{\circ} \mathrm{C}$. Plasma progesterone concentrations were measured by radioimmunoassay after column chromatography of $50 \mu \mathrm{l}$ plasma samples, as described in Jones and Rose (1992).

\section{Vaginal smears}

Smears were obtained every 2 days as described in Rose (1987); daily samples were obtained near oestrus. After fixation, the smears were stained with modified Shorr's stain. The smears were evaluated quantitatively by the calculation of the karyopycnotic index and the leucocytic index as in Peters and Rose (1979) after Hughes and Dodds (1968). The karyopycnotic index is the percentage of epithelial cells with pycnotic nuclei, whereas the leucocytic index is the percentage of all cells that are leucocytes. One hundred cells were counted each time. Means and standard errors were calculated for these two indices for the 10 days before and after oestrus (including the day of oestrus). Ten complete cycles were obtained from the three females.

\section{Results}

\section{Body temperature}

All three bettongs demonstrated a diurnal temperature rhythm typical of a nocturnal mammal; the minimum daily temperature was taken to be the basal body temperature $\left(36.17 \pm 0.16^{\circ} \mathrm{C}\right)$ and occurred at midday and the maximum occurred at $01: 00 \mathrm{~h}\left(37.47 \pm 0.16^{\circ} \mathrm{C}\right)$. The hourly means ( \pm SEM) for a continuous period of 22 days from the three bettongs are shown (Fig. 1).

During the oestrous cycle, the basal body temperature remained high from 10 days before to 3 days before oestrus, after which there was a fall in temperature until just before oestrus (day 0) (Fig. 2a). A small peak occurred at oestrus, followed by a fall to the minimum value for the whole cycle on day 2 . There was an increase in basal body temperature on day 3 which reached the mean maximum temperature for the period monitored on day 4 . The analysis of variance was significant (Table 1). There were significant differences between the three bettongs $(P>0.0001)$ and significant differences $(P>0.0001)$ between days of the oestrous cycle; however, there was no significant interaction $(P<0.5984)$ indicating that the profiles were parallel with time. The calculated mean differences between each day were compared with twice the overall standard error of the difference between the means and it was found that the minimum obtained on day 2 after oestrus was significantly Downloaded from Bioscientifica.com at 04/26/2023 09:43:02AM 


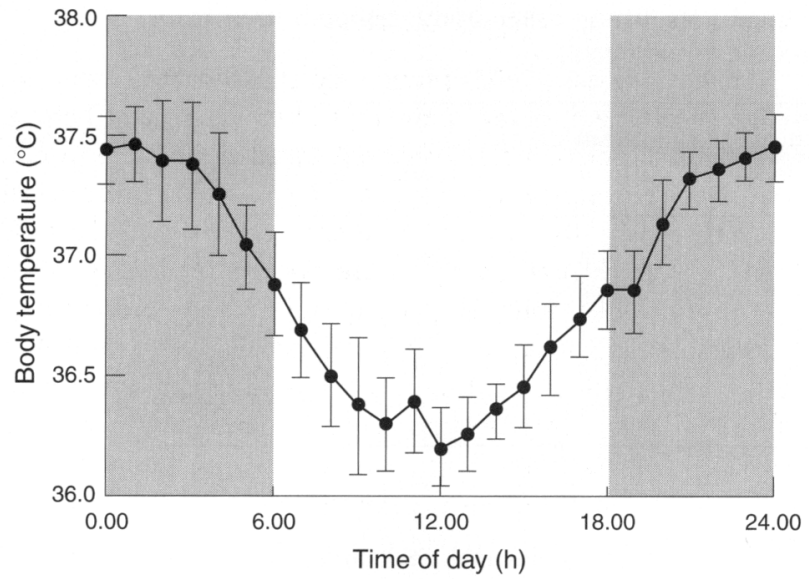

Fig. 1. Diurnal rhythm of body temperature in three female Tasmanian bettongs Bettongia gaimardi. Measurements were taken for 22 consecutive days for each animal and values are presented as means \pm SEM. Hatched areas indicate periods of darkness.

lower $(P<0.05)$ than the mean values obtained from 10 days before to 3 days before oestrus. The rise in temperature on day 3 was also significantly different $(P<0.05)$ from that at day 2 and the difference in basal body temperature remained significant until day 10 . The value obtained on the day of oestrus was not significantly different from the day before or the day after oestrus. In addition, the two low values on 2 days and 1 day before oestrus were significantly different $(P<0.05)$ from the higher temperatures 9 days and 6 days before oestrus.

\section{Progesterone profile}

Progesterone concentrations gradually increased from $0.8 \pm 0.2 \mathrm{ng} \mathrm{ml}^{-1} 10$ days before oestrus to $1.3 \pm 0.3 \mathrm{ng} \mathrm{ml}^{-1}$ on 1 day before oestrus (Fig. 2b). At oestrus, there was a rapid decrease in progesterone concentrations, which remained low until day 3 after oestrus when there was a transient peak $\left(0.8 \pm 0.3 \mathrm{ng} \mathrm{ml}^{-1}\right)$.

\section{Vaginal smears}

Cyclic changes in the vaginal smear were noted in all females. The smear indices remained fairly constant in the 10 days before oestrus; however, the smear thickened several days before oestrus. The disappearance of leucocytes and mucus was the most abrupt of the changes in the smear cycle and occurred on the day of oestrus (Fig. 2c). This was followed by a cornification after oestrus which lasted for 5-6 days. The sudden absence of leucocytes which heralded oestrus was corroborated by the presence of spermatozoa in the smear when males were present.

\section{Discussion}

Vaginal smears have been the standard procedure for monitoring reproductive cycles of marsupials from the early work of
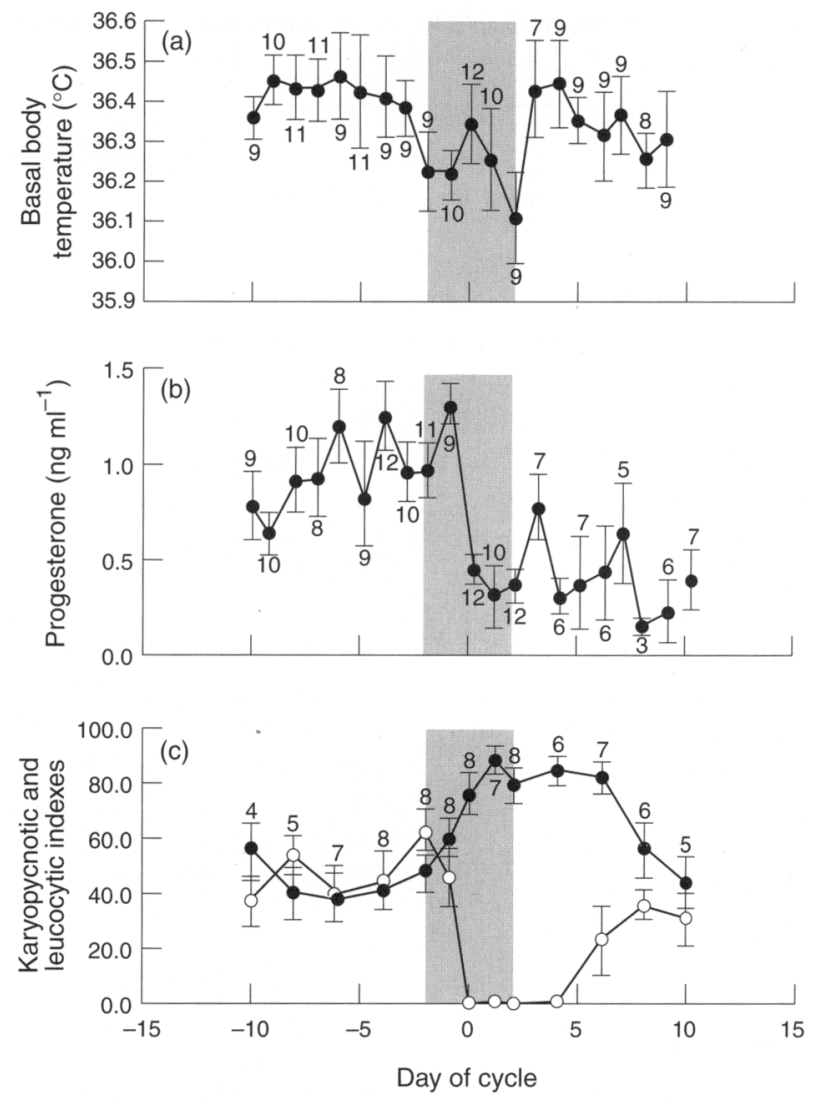

Fig. 2. Changes in (a) basal body temperature, (b) progesterone values and (c) (•) karyopycnotic and (o) leucocytic indexes during the reproductive cycle in Tasmanian bettongs (Bettongia gaimardi). The number of animals in each sample is given next to the error bar. The three sets of samples were not collected simultaneously, and additional animals were used for determination of progesterone concentrations. The hatched areas indicate oestrus \pm 2 days.

Hartman (1923) on the opossum and Sharman (1955) on the Australian wallaby Setonix brachyurus to the recent mathematical analysis of the vaginal smears of the tammar wallaby (Macropus engenii) by Poole et al. (1992). In the study described here, quantitative data on the changes in epithelial cells and leucocytes on the 10 days before and after oestrus in the Tasmanian bettong are presented.

The most obvious changes occur near oestrus, as in most other marsupials (Tyndale-Biscoe and Renfree, 1987). At oestrus, presumably under the influence of oestrogen, the epithelial cells rapidly cornify, their nuclei shrink and leucocytes disappear from the smear for 5 days. These changes in the smear are associated temporally with a rapid fall in progesterone concentrations just before oestrus. A number of other macropodids also have a period of vaginal cornification after oestrus as detected by the vaginal smear method. Peters and Rose (1979) suggested that the influx of cornified cells from the lateral vaginae masked changes in the epithelium of the posterior vaginal sinus. Poole et al. (1992), working on the tammar wallaby Macropus eugenii, also showed that cornified cells are predominant in the smear for 6 days after oestrus but gave no details on leucocytes. 
Table 1. Analysis of variance for two-factor repeated measures using basal body temperatures from three bettongs over twelve oestrous cycles

\begin{tabular}{lccccc}
\hline Source & $\begin{array}{c}\text { Degrees } \\
\text { of freedom }\end{array}$ & $\begin{array}{l}\text { Sum of } \\
\text { squares }\end{array}$ & $\begin{array}{c}\text { Mean } \\
\text { square }\end{array}$ & F test & $P$ value \\
\hline Between subjects (A) & 2 & 6.413 & 3.206 & 36.413 & 0.0001 \\
Subjects within groups & 9 & 0.792 & 0.088 & & 0.0001 \\
Repeated measures (B) & 20 & 2.501 & 0.125 & 3.079 & 0.5984 \\
Interaction (AB) & 40 & 1.507 & 0.038 & 0.927 & \\
B $\times$ subjects within groups & 180 & 7.31 & 0.041 & & \\
\hline
\end{tabular}

At oestrus, and for several days thereafter, leucocytes are almost undetectable in the smears from the bettong, the macropodid Thylogale billardierii (Rose and McCartney, 1982) and the common wombat Vombatus ursinus (Peters and Rose, 1979). Fletcher (1989) working with the dasyurid marsupial, Dasyuroides brynei, showed that leucocytes first appeared in the urine on the day after mating and were seen for 8-11 days after oestrus. Pilton and Sharman (1962) found that leucocytes reappeared in the vaginal smears of brushtail possums (Trichosurus vulpecula) on the day after oestrus and were abundant for a further 2-5 days before decreasing.

Rose (1987) reported qualitative changes in vaginal smears of Tasmanian bettongs and that report is confirmed and extended by the detailed quantitative data presented here. Analysis of vaginal smears, particularly when the data are quantified, is a simple and precise method for monitoring the oestrous cycle in this species but it involves the regular capture of females which may be impracticable. In addition, if capture is stressful to the animal, it may affect the duration of the cycle being monitored (Jones and Rose, 1992). To our knowledge, however, there are no reports indicating that marsupial oestrous cycles monitored by the vaginal smear method differ in duration from cycles monitored by other means.

A circadian rhythm of the basal body temperature was found to occur in the female bettongs. Similar results were obtained by Rose et al. (1990) with male bettongs; there was a small non-significant difference between the sexes in the difference between the average daily maximum and minimum $\left(1.3^{\circ} \mathrm{C}\right.$ for females in this study and $1.6^{\circ} \mathrm{C}$ for males). As expected for a nocturnal mammal, the basal body temperature was lower during the day, when the animal is resting. Similar temperature rhythms have been found in other nocturnal marsupials such as wombats (Peters and Rose, 1979) and opossums (Treagust et al., 1979). There were significant variations in the basal body temperature during the reproductive cycle in the female bettongs; the major changes are associated with oestrus and ovulation. Tyndale-Biscoe and Renfree (1987) commented upon the (then unpublished) changes in basal body temperature observed in bettongs by Rose (1984) as follows: "This bears such a close resemblance to the progesterone profile of other macropodoids that they may be causally related in the same way as they are known to be in humans and the rhesus monkey."

In humans, basal body temperatures are raised within a day of ovulation (Simpson and Halberg, 1974) and remain so during much of the luteal phase. In bettongs, however, there is a small (but not significant) peak in basal body temperature at oestrus, followed by a larger significant peak on days 3-4 after oestrus. This second peak is coincident with a short-lived peak in plasma progesterone $\left(0.8 \mathrm{ng} \mathrm{ml}^{-1}\right)$ on day 3 , similar to that found by Jones and Rose (1992) at day 4 after removal of pouch young in the same species. Such a progesterone peak is also found in several other macropodid species (Cake et al., 1980; Hinds and Tyndale-Biscoe, 1982; Walker and Gemmell, 1983; Curlewis et al., 1987; Hinds and Smith, 1992). In the latter half of the oestrous cycle, the basal body temperature remains high before falling 2 days before oestrus. The raised basal body temperature correlates with increased concentrations of progesterone and it is probable that increase in basal body temperature after oestrus occurs in many other marsupials.

The peak in basal body temperature on day 3 after oestrus is possibly due to the thermogenic action of the peak in progesterone with which it is temporally correlated. The smaller (and not significant) peak in basal body temperature at oestrus is more difficult to explain. A small transient peak in basal body temperature also occurs at oestrus in other mammals, for example, rats (Yochim and Spenser, 1976) and wombats (Peters and Rose, 1979). It is possible that behavioural changes at oestrus, such as increased activity, result in higher temperatures as suggested by Peters and Rose (1979) and Rose (1984).

In bettongs, the raised basal body temperature in the second half of the cycle is likely to be due to the thermogenic effect of progesterone (Freeman et al., 1970) and of extravascular or vaginal leucocytes (Simpson and Halberg, 1974). Graham et al. (1977) speculated that in chimpanzees, the temperature changes after ovulation varied with the progesterone:oestrogen ratio; however, oestrogen concentrations were not measured in the present study. Variations in the progesterone:oestrogen ratio might explain why there is not always a temporal correlation between basal body temperature and progesterone; for example, the peak in progesterone at day 7 has no coincident rise in basal body temperature. Begley et al. (1980) suggested that the increase in basal body temperature in women is due either to metabolic effects from pregnanediol or to the interaction of progesterone with hypothalamic receptors, resetting the hypothalamic 'thermostat'. These effects may be mediated by noradrenaline (Zuspan and Zuspan, 1979).

The subsequent fall in basal body temperature corresponds with decreases in the concentrations of plasma progesterone and numbers of leucocytes in the vaginal smears. The body temperature variations associated with the oestrous cycle are Downloaded from Bioscientifica.com at 04/26/2023 09:43:02AM 
similar to those found in one other marsupial for which there are measurements, the common wombat (Vombatus ursinus) (Peters and Rose, 1979). However, no correlation was found between the oestrous cycle and basal body temperature for brushtail possums (Trichosurus vulpecula) (Halse and Rose, 1988).

We conclude that monitoring basal body temperature may be used successfully to infer the stage of the oestrous cycle in bettongs; although in practice, the time of oestrus could only be determined in retrospect. It seems unlikely that measurements of body temperature will replace more conventional means of monitoring reproductive cycles in mammals. However, when it is not possible to capture animals regularly for the purpose of vaginal smears or blood sampling, it may be useful as a method that does not, after the initial implantation of the temperature sensor, require handling or even viewing the animal. Values of body temperature obtained daily at or near mid-day should suffice to determine oestrus. Coupled with field telemetric measurements of movements and activity, monitoring of basal body temperature could be a very useful adjunet to ecological studies.

This work was supported, in part, by a research grant from the Australian Research Council. The authors would like to thank R. Swain and M. Hindell (Zoology Department, University of Tasmania) for their comments on the manuscript and L. Barmuta for advice on the statistical analyses.

\section{References}

Begley DJ, Firth JA and Hoult JRS (1980) Human Reproduction and Developmental Biology. Macmillan Press, London.

Cake MH, Owen FJ and Bradshaw SD (1980) Difference in concentration of progesterone in the plasma between pregnant and non-pregnant quokkas (Setonix brachyurus) Journal of Endocrinology 84 153-158

Curlewis JD, White AS and Loudon ASI (1987) The onset of seasonal quiesence in the female Bennett's wallaby (Macropus rufogriseus rufogriseus) Journal of Reproduction and Fertility 80 119-124

Fletcher TP (1989) Plasma progesterone and body weight in the pregnant and non-pregnant kowari, Dasyuroides brynei (Marsupialia:Dasyuridae) Reproduction, Fertility and Development 1 65-74

Freeman ME, Crissman JK Jr, Louw GN, Butcher RL and Inskeep EK (1970) Thermogenic action of progesterone in the rat Endocrinology 86 717-720

Graham CE, Warner H, Misener J, Collins DC and. Preedy JRK (1977) The association between basal body temperature, sexual swelling and urinary gonadal hormone levels in the menstrual cycle of the chimpanzee Journal of Reproduction and Fertility 50 23-28

Halse S and Rose RW (1988) Variation in the basal body temperature of the common brushtail possum (Trichosurus vulpecula) in Tasmania Mammalia 52 225-231

Hartman CG (1923) The oestrous cycle in the opposum American Journal of Anatomy 32 535-421
Hinds LA and Smith MJ (1992) Evidence from plasma progesterone concentrations for male-induced ovulation in the brush-tailed bettong, Bettongia pencillata Joumal of Reproduction and Fertility 95 291-302

Hinds LA and Tyndale-Biscoe CH (1982) Plasma progesterone levels in the pregnant and non-pregnant tammar Macropus eugenii Journal of Endocrinology 93 99-107

Hughes HE and Dodds TC (1968) Handbook of Diagrostic Cytology pp 71-72. Baltimore, Williams and Wilkins, Edinburgh

Jones SM and Rose RW (1992) Progesterone levels in the pregnant Tasmanian bettong (Bettongia gaimardi) General and Comparative Endocrinology 87 $178-182$

Peters DG and Rose RW (1979) The oestrous cycle and basal body temperature in the common wombat (Vombatus ursinus) Journal of Reproduction and Fertility 57 453-460

Pilton PE and Sharman GB (1962) Reproduction in the marsupial Trichosurus vulpecula Journal of Endocrinology 25 119-136

Poole WE, Westcott M and Simms NG (1992) Determination of oestrus in the female tammar, Macropus eugenii, by analysis of cellular composition of smears from the reproductive tract Wildlife Research 19 35-46

Rose RW (1982) Tasmanian bettong Bettongia gaimardi: maintenance and breeding in captivity. In The Management of Australian Mammals in Captivity Ed. DD Evans. Zoological Board Victoria, Melbourne

Rose RW (1984) The Reproductive Biology of the Tasmanian bettong, Bettongia gaimardi. PhD Thesis, University of Tasmania

Rose RW (1986) Control of pouch vacation in the Tasmanian bettong Australian Journal of Zoology 34 485-491

Rose RW (1987) Reproductive biology of the Tasmanian bettong (Bettongia gaimardi: Macropodidae) Journal of Zoology 212 59-67

Rose RW and McCartney DJ (1982) Reproduction of the red-bellied pademelon, Thylogale billardierii (Marsupialia) Australian Wildlife Research 9 27-32.

Rose RW, Swain R and Bryant SL (1990) Body temperature: rhythm and regulation in the Tasmanian bettong (Bettongia gaimardi) Comparative Biochemistry and Physiology 97A 573-576

Sharman GB (1955) Studies on marsupial reproduction. II. The oestrous cycle of Setonix brachyurus Australian Journal of Zoology 3 44-55

Shepherd N (1990) Capture myopathy. In Care and Handling of Australian Native Animals pp 143-147 Ed. S Hand. Surrey Beatty \& Sons Pty Ltd, Chipping Norton

Simpson HW and Halberg EE (1974) Menstrual changes in the circadian temperature rhythm in women. In Biorhythms and Human Reproduction Eds M Ferin, F Halberg and EM Richart. Wiley and Sons, New York

Treagust DF, Folk GE, Randall W and Folk MA (1979) The circadian rhythm of body temperature of unrestrained oppossums, Didelphis virginia Journal of Thermal Biology 3 251-255

Tyndale-Biscoe CH (1968) Reproduction and post-natal development in the marsupial Bettongia lesueur (Quoy and Gaimard) Australian Journal of Zoology 16 577-602

Tyndale-Biscoe $\mathrm{CH}$ and Renfree MB (1987) Reproductive Physiology of Marsupials. Cambridge University Press, Melbourne

Walker MT and Gemmell RT (1983) Plasma concentrations of progesterone, oestradiol-17 $\beta$ and 13,14-dihydro-15oxo-prostaglandin $\mathrm{F} 2 \alpha$ in the pregnant wallaby (Macropus rufogriseus rufogriseus) Journal of Endocrinology 97 369-377

Yochim JM and Spenser F (1976) Core temperature in the female rat: effect of ovariectomy and induction of pseudopregnancy American Journal of Physiology 231 361-365

Zuspan KJ and Zuspan FP (1979) Basal Body Temperature. In Human Ovulation: Mechanisms, Predictions, Detection and Induction. Ed. ESE Hafez. Elsevier, North Holland 